\title{
Frontiers of Nanofiltration, Ultrafiltration and the future of global water shortage - a deep and visionary comprehension
}

\author{
Sukanchan Palit \\ Department of Chemical Engineering, University of Petroleum and Energy Studies, \\ Post-Office-Bidholi via Premnagar, Dehradun - 248007, Uttarakhand, India \\ Mobile No. 08958728093 , 033-24026947 \\ E-mail address: sukanchan68@gmail.com , sukanchan92@gmail.com
}

\begin{abstract}
The world of environmental engineering science is moving briskly and steadfastly in a newer vision and a newer age ahead in the civilisation's progress. Global water shortage has become a primordial issue in present day human civilization. Environmental regulations and ecological restrictions has to be reassessed and rejudged at this critical juncture of history and time. In a similar vein the importance of membrane science and the applicability of environmental engineering techniques stands in the midst of immense optimism and scientific vision. Analytically, membrane separation science will bring environmental engineering science to the newer vision of zero discharge norms. Zero discharge norms and environmental engineering paradigm has an umbilical cord which has a decisive effect on ecological balance. The primordial and the decisive factor in global water shortage is the issue of ground water contamination and its subsequent remediation. Nanofiltration, ultrafiltration and other membrane separation processes in today's scientific world and scientific vision stands in the midst of inimitable hope and optimism.
\end{abstract}

Keywords: vision; nanofiltration; ultrafiltration; water; sustainability; environment

\section{INTRODUCTION}

History, application and vision of nanofiltration and ultrafiltration needs to be reassessed and readjudicated in view of the global water shortage. Membrane separation processes have unsurpassed vision. Industrial pollution control and defunct environmental sustainability are bane to civilisation's progress and boon to inevitable disaster. In such a critical juncture of history, time and vision, the world of challenges needs to be surpassed. History of human mankind is steadily and briskly moving from one newer vision towards another. The question of environmental sustainability has become the primordial issue of the newer scientific generations.

Zero discharge norms and environmental catastrophes have catapulted human civilization to a newer vision of immense environmental engineering future. The doctrine of environmental engineering science is witnessing a new dawn of scientific fortitude. 


\section{Vision and objective of the present treatise}

Vision and aim of the present treatise is wide, vast and versatile. Human mankind is moving briskly and steadily from one visionary scientific generation to another. Environmental engineering science, separation tools and environmental sustainability are in a similar manner are striving forward towards a purposeful vision.

Our aim and objective is to delineate the future perspective and future directions in the field of nanofiltration and ultrafiltration and the interlinked domain of global water shortage. A cogent and deep insight marks the ushering in of the intricacies of membrane separation processes, its vast application areas and its far-reaching implications as regards global water shortage. An engineer's wide perspective is justified and immensely validated as one opens the wide doors of innovation in the field of membrane separation tools. ${ }^{1-3}$

\section{History of environmental engineering science, immense optimism and vibrant hope}

History of environmental engineering science is moving briskly and steadily from one visionary mission to another. Nanofiltration and ultrafiltration are the present generation science and technology. Groundwater remediation and desalination are the focal points in the application of membrane separation processes.

Success, scientific research pursuit and vibrant hope needs to be reassessed and restructured.

Arsenic contamination of groundwater and heavy metal concentration of groundwater are the vicious effects of the immense progress of environmental engineering science. Future dimensions and future scientific advancements needs to be revamped.

\section{FUTURE COMPREHENSION AND DEEP UNDERSTANDING}

\section{Definition of membrane separation processes, nanofiltration and ultrafiltration}

Membrane separation processes, nanofiltration and ultrafiltration are moving from one generation of scientific innovation over another. The definition will be delineated from the famous Loeb-Sourirajan model of membrane separation techniques. ${ }^{1-3}$

Membrane separation processes can be classified into a wide variety of separation procedures such as nanofiltration, ultrafiltration, reverse osmosis, pervaporation, electridialysis etc.

The vision is clear, wide and definitive. Membrane science is in the path of being an effective separation technique and a visionary procedure. Loeb- Sourirajan model revolutionized the path of science and opened up new vistas of sound scientific vision and effective scientific judgement.

Progress of human civilization is moving in the avenue of immense scientific fortitude and scientific steadfastness. The world of challenges needs to be redefined and restructured with the progress of human civilization. 


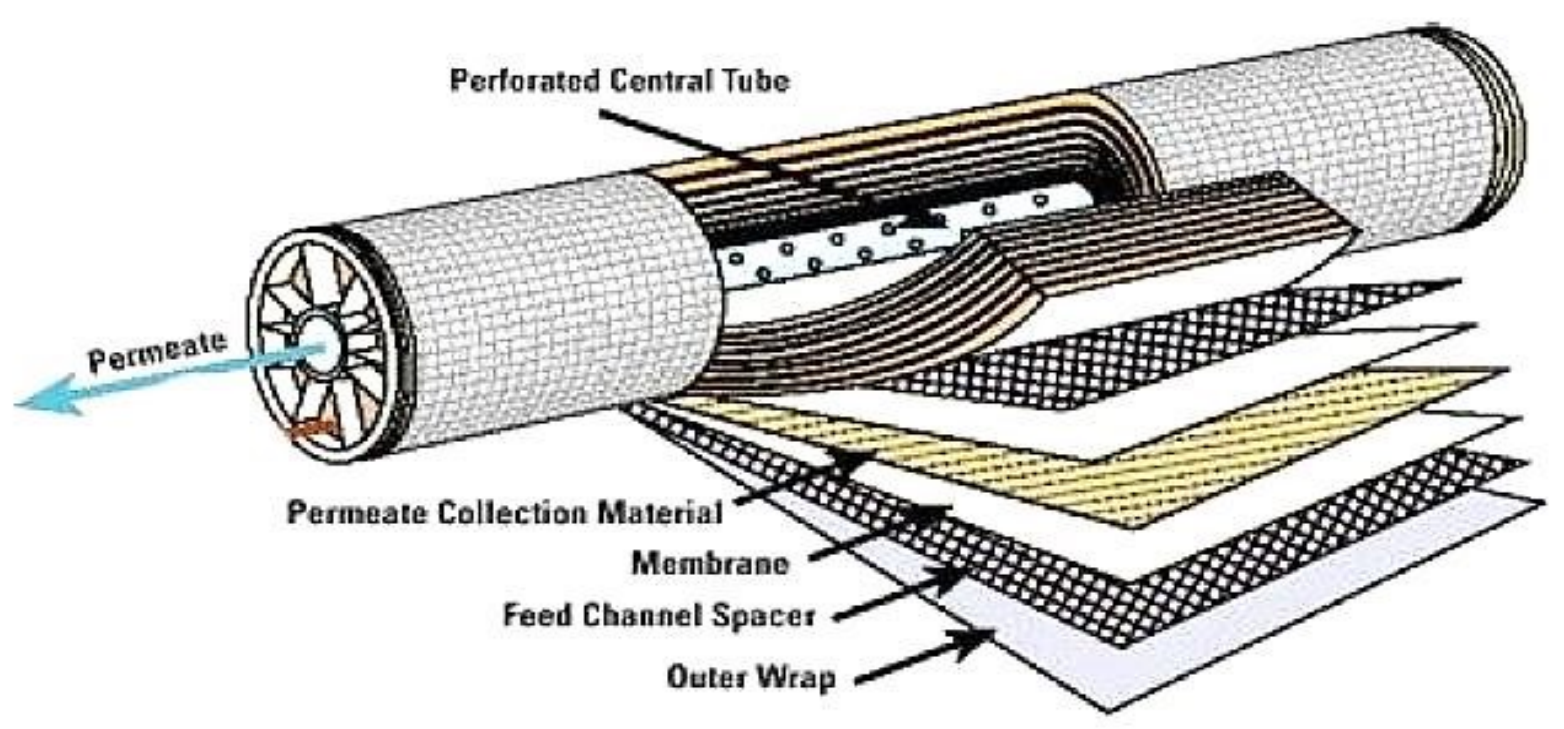

Figure 1. A diagrammatic representation of a spiral-wound membrane element [19].

\section{Doctrine of nanofiltration and ultrafiltration}

Doctrine of nanofiltration, ultrafiltration and membrane science are wide, varied and versatile. The boons of the progress of environmental engineering science are surely catapulting the human civilization to a newer vision and a newer generation. Nanofiltration and ultrafiltration today stands as an effective separation tool to resolve environmental engineering catastrophes. Science and technology needs to be redefined and re-envisioned with the march of human civilization. Scientific jargons needs to be obliterated and redefined. ${ }^{1-3}$

\section{Groundwater remediation and the future of global water shortage}

Groundwater remediation and future of global water shortage today stands in the midst of immense steadfastness, hope and optimism. The challenges are surmounting over the years. Environmental engineering and application of nanofiltration and reverse osmosis are plunging towards creation of one engineering marvel over another. In today's world, progress of human mankind is inevitably linked with provision of clean drinking water. Environmental sustainability is ushering in a new era of human development. ${ }^{4-7}$

\section{Bioremediation, bio-ozonation and application of advanced oxidation processes}

Bioremediation and bio-ozonation techniques are surpassing wide and vast visionary frontiers. In today's environmental engineering scenario, bio-ozonation is an immense newer thought driven process. Bioremediation combined with advanced oxidation processes such as primarily ozonation will enhance groundwater remediation and groundwater decontamination. Integration of advanced oxidation processes in one such widely challenging vista of research. The world of environmental sustainability needs to be restructured and envisioned with the advent of novel separation processes. ${ }^{18}$ 


\section{Vision, objectives and purposeful mission in the field of membrane science}

Vision and purposeful objectives in the membrane science is opening up new frontiers and new directions in scientific thrust and scientific endeavour. The greatness of challenges needs to be redrafted. Ground water remediation is not immature but visionary. In such a critical juxtaposition, application of membrane science in solving major and incisive global water shortage problems is of utmost importance.

History of membrane science and engineering today stands in the midst of a backdrop of immense scientific vision and scientific anticipation. A scientist's as well as an engineer's far-reaching vision about the application and its difficulties will be extremely emboldened with new discoveries and new scientific validations. The ever-increasing concerns of fouling, cleaning and the effect of concentration polarization will be surely obliterated with the wide passage of time.

The question which human civilization faces today is of environmental sustainability, obliteration of environmental catastrophes and proper and sound environmental sustainable development. Environmental pollution control and the scenario of global water shortage are two such vital issues for the vision of future.

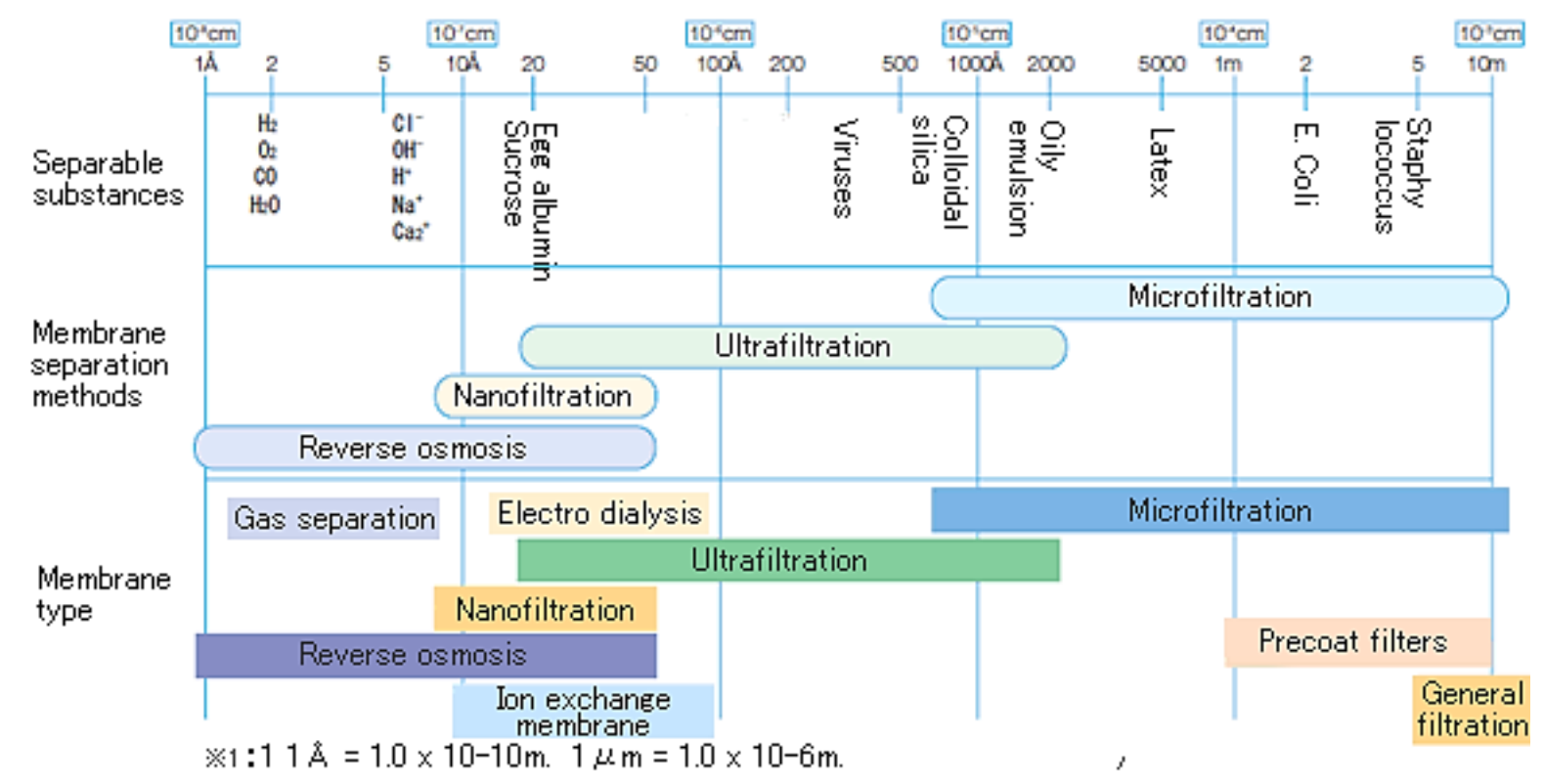

Figure 2. Classification of various membrane separation processes [19].

\section{Design factors affecting flux in membrane technology}

Design factors reign supreme in the critical juncture of application of membrane technology. The major emphasis and immense thrust is in the design of equipment and its operation is to reduce the effects of concentration polarization. Reduction of concentration polarization ushers in reduction of pressure, reduction of concentration at membrane surface and reduction of solids in feed. Again reduction of concentration at membrane surface involves with major thrust on mixing perpendicular to membrane, low concentration factor, prevent concentration at membrane surface and increase back transfer of solids. ${ }^{4-7}$ 


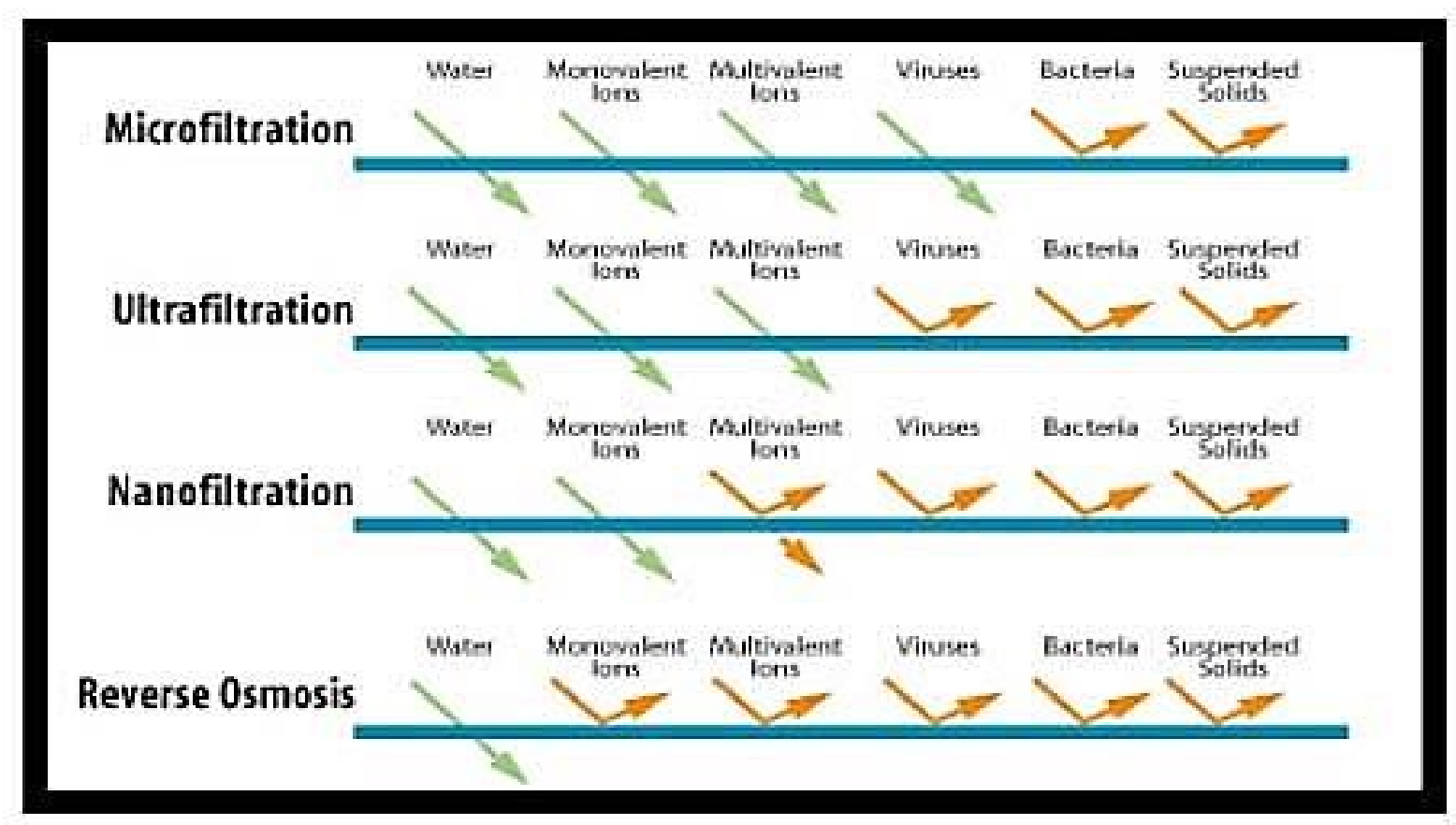

Membrane Process Characteristics

Figure 3. Different membrane process characteristics [19].

\section{Fouling and cleaning - the difficulties of membrane operation}

Fouling and cleaning are the vital points and primordial issues of the success of a membrane separation process ${ }^{8-10}$. History of membrane technology today stands in the midst of immense scientific vigour, scientific vitality and scientific justification. Man's scientific vision and scientific judgement are emboldened by the tools of present day science and technology ${ }^{19}$.

\section{Characteristics of fouling}

Characteristics of fouling and its phenomenon are the most widely accepted difficult phenomena which needs to tackled with extensive scientific pursuit. Scientific validation and scientific vision needs to be restructured ${ }^{19}$.

A major limiting step in membrane technology is "fouling" of the membrane. Fouling manifests itself as a decline in flux with time of operation. Fouling problems were the single most primordial issue for the increasingly slow acceptance of membrane engineering in its early days. In the past decade major scientific advances, scientific vision and scientific pursuit has resulted in major understanding of fouling phenomena and slowly alleviated its effects. ${ }^{1}$

\section{Consequences of fouling}

An obvious result and future vision of fouling is higher capital expense caused by the lower average flux over a process cycle. In addition, depending on the nature and extent of fouling, restoring the flux may require powerful cleaning agents, which may reduce the operating life of the membrane. This continues to be a problem with cellulose acetate (CA) membranes, which have a limited $\mathrm{pH}$, temperature, and cellulose acetate range. ${ }^{8-10,18}$ 


\section{Mathematical models of fouling}

Most models relate the flux to the time or volume permeated and generally take an exponential form, considering the shapes of the fouling curves. Several models have been developed based on pore blocking mechanism developed for dead-end filtration. In one case, it is assumed that only a fraction of the pores is completely blocked by the particles. This fraction is proportional to the amount of permeate flow through the membrane. ${ }^{11-13,18}$

\section{Factors affecting fouling}

Since fouling in its truest vision is a result of specific interactions between the membrane and various solutes in the feedstream, and perhaps between the adsorbed solute and other solutes in the feedstream, it is difficult to establish general theories about the nature and extent of fouling that will be universally applicable. Each component of a feedstream will react differently with the membrane: conformation, charge, zeta potential, hydrophobic interactions, and other factors will have a significant bearing on these membrane - solute interactions. $^{14-18}$

\section{Flux enhancement}

There are several strategies to maximize flux. Most involve moving the fluid and some involve moving the membrane. Some additional strategies that involve manipulating the net transmembrane pressure and fluid-membrane interactions are as follows: ${ }^{14-18}$

- Turbulent promoters/inserts/baffles.

- Backflushing, pulsing, shocking and washing.

- Uniform transmembrane pressure/ co-current permeate flow.

- Permeate back pressure.

- Intermittent jets.

- Pulsatile flow.

- Electrical methods. ${ }^{17,18}$

\section{Cleaning membranes}

Cleaning is the removal of foreign material from the surface and body of the membrane and associated equipment. The vast majority of the literature over the past 2 decades has focused on "fouling" rather than cleaning, even though what appears to be fouling may really be a cleaning problem.

Considerable progress has been made in this period on understanding the interactions between the foulants (soil), the membrane and the operating conditions during cleaning. ${ }^{18}$

Cleaning and sanitizing membranes is desirable for several reasons:

1) Laws and regulations may demand it in certain applications(eg: the food and biotechnology industries). ${ }^{18}$

2) Reduction of microorganisms to prevent contamination of the product streams. ${ }^{18}$

3) Process optimization. ${ }^{18}$

\section{Vision of membrane science, application, advantages and disadvantages}

Advantages and disadvantages of membrane science are wide and many. The efficiency and effectiveness of membrane science are the focal points of scientific striving and the great 
primordial issues which needs to be tackled and environmental pollution control harnessed. Man's vision needs to be channelized in a newer direction and newer visionary path with the progress of civilization.

\section{Environmental sustainability, progress of science and technology and the ultimate vision}

Environmental sustainability is surely not a jargon in today's world of environmental sustainability. A newer vision needs to be redirected in view of the environmental pollution control scenario. History of science and technology, progress and march of science needs to be redefined. Progress of engineering, the incisive question of environmental and also energy sustainability and the path towards successful scientific endeavour will in future usher in a new era of definitive and purposeful vision. The challenges needs to be surmounted with the immense march of science. ${ }^{17,18}$

\section{Science, technology, environmental engineering science and progress of human mankind}

Environmental engineering science and progress of human mankind are the torchbearers of tomorrow. History of catastrophes and environmental disasters are ushering in a new thought of environmental engineering. The vision of tomorrow is awe-inspiring. ${ }^{17,18}$

Progress of human mankind is dependent on progress of science and technology. Human endeavour in today's present day civilization is surpassing visionary boundaries and far-reaching frontiers. Man's scientific pursuit is today at stake. The world of challenges are surmounting with the passage of time. At this critical juncture of time and crucial juxtaposition of time and history, man's scientific endeavour needs reshaping and a rethought is needed. History of human civilization is today in deep peril. The question of environmental sustainability will surely usher in a newer vision and a new dawn of civilization. ${ }^{17,18}$

\section{Global water shortage, vision of drinking water treatment and the progress of research}

Global water shortage and the purposeful vision of drinking water treatment has an umbilical cord whose cords can never be severed. The world of varied challenges, the question of sustainability and the immense progress of water engineering will widely open up new generations of thought procedure and new vistas of scientific endeavour.

\section{Technologies for water treatment and the progress ahead}

The progress of civilization is at stake in today's world. The challenges of global water shortage, technologies of drinking water treatment and desalination of water are the prime objectives for a positive vision for the future. The progress of civilization is widely visionary and purposefully far-reaching. Future frontiers, future directions and future vision in the domain of water treatment needs to be re-challenged and re-envisioned. ${ }^{18}$

\section{Desalination and the visionary future}

Desalination, drinking water treatment and global water shortage are interlinked in today's human mankind. Provision of clean drinking water today stands as a major and primordial issue in the economic growth of a nation. An engineer's vision needs to be reassessed and restructured with the turn of every decade in this present century. Progress of science and engineering is vast and versatile in the present century. Innovation and 
discoveries along with economic growth of a nation will go a long way in the validation of laboratory scale inventions to well being of civil society. ${ }^{18}$

\section{Arsenic groundwater contamination and future of global water shortage}

Arsenic groundwater contamination is causing havoc to the developing as well as developed countries of the world. Challenges are immense and the future vision of arsenic groundwater remediation is faced with lot of barriers and immense pessimism. In such a crucial juxtaposition, application of nanofiltration and ultrafiltration will surely go a long way in evolving a new futuristic vision. ${ }^{17,18}$

\section{Advanced oxidation processes and the immediate vision}

Advanced oxidation processes has immense and versatile potential. It is one of the major novel wastewater water treatment procedures. The path towards progress is wide and far-reaching. In today's scientific world and scientific domain, application of novel separation processes and advanced oxidation processes are surpassing visionary frontiers of vast scientific endeavours and scientific truth.

\section{Bioremediation and bio-ozonation}

Bioremediation and bio-ozonation will surpass many visionary frontiers. The challenges in the field of bioremediation are already proven but bio-ozonation is the new vista of scientific endeavour. Environmental engineering is moving steadily from one visionary progress towards another. The challenges, difficulties and scientific barriers needs to be revamped and readjudicated with the passage of time. ${ }^{17,18}$

Bio-ozonation is the next generation wastewater remediation tool. It is a combination of biochemical techniques and of advanced oxidation processes such as ozonation. Scientific vision needs to be rejustified at every step of wide scientific endeavour. Bioremediation and bio-ozonation is the next generation visionary techniques which will witness unsurpassed frontiers. The scientific challenges needs to be redrafted and reassessed. ${ }^{17,18}$

\section{Membrane science, progress of science and technology and the visionary path ahead}

The visionary path ahead is far-reaching and ground-breaking. The scientific research pursuit needs to be reassessed and readjudicated with the progress of civilization. In this age and civilization of immense scientific understanding, the question of zero discharge norms has become the focal point of imminent environmental catastrophes and scientific disasters. Man's vision, scientific pursuit and scientific validation needs to be readdressed in a vehement and glorious manner ${ }^{17,18}$.

Inevitable march of science and technology, history of scientific endeavour and scientific sagacity

Scientific sagacity, scientific cognizance and the march of science and engineering are all moving towards a definitive and purposeful vision. The aim, mission and goal of the immense research pursuit are relevant to the success of the march of human mankind and positively towards the well being of human society. Articulation of scientific cognizance will be the newer vision of tomorrow. ${ }^{17,18}$

Scientific sagacity is a boon to the progress of human civilization. History needs to be reshaped and restructured at this critical period of environmental sustainability and holistic 
human development. Industrial development, progress of mankind and march of engineering are the coinwords of a newer vision. History is repeating itself at every turn of a decade in this present century. The world of challenges and the immense difficulties needs to be overcome. ${ }^{17,18}$

\section{A visionary comprehension and a deep insight into the engineering of membrane separation processes}

A deep insight and cogent understanding will lead our human civilisation to a newer visionary future. The scientific pursuits needs to be challenged and vision needs to be surpassed. The scientific perspectives needs to be revisited with the imminent water shortage crisis as its vision.

Visionary comprehension and cogent insight will go a long way in opening up the innovative doors of intuition of tomorrow. Global water shortage has a negative impact on human progress. Drinking water provision is one of the visionary parameters of growth of human civilization. Membrane separation processes can solve immense desalination and water shortage problems. The difficulties and challenges needs to be overcome with the advent of visionary scientific endeavour. Heavy metal contamination of the groundwater is a serious challenge for the future. ${ }^{17,18}$

\section{The world of challenges, the definitive vision and the progress of science ahead}

The world of inevitable challenges, the difficulties and barriers and the march of civilization ahead will surely go a long way in evolving new visionary tools to tackle environmental engineering problems. In today's human civilization, environmental engineering tools and global water shortage have an umbilical cord which can never be severed. Membrane science and technology is the visionary path towards progress. Progress of science and engineering will surpass many visionary frontiers if the fruits of application areas of membrane science are validated.

\section{Membrane separation processes, the world of difficulties and the visionary road ahead}

The world of challenges and the visionary road ahead are the primary focal points of the present day human mankind. Membrane science and technology is gearing up towards surpassing one frontier over another. The history of challenges needs to be readjudicated and revamped. Membrane separation processes is moving with much steadfastness and firmness towards a newer vision tomorrow. The visionary road ahead needs to scientifically rejudged with the evolution of environmental regulations and the scientific innovations of separation tools. ${ }^{17,18}$

\section{Environmental sustainability and the future of global water shortage}

Environmental sustainability is a primordial issue to tackle for the future of human civilization. The challenges and frontiers are wide, versatile and far-reaching. Man's as well as a scientist's vision needs to be restructured with the critical view of the issue of global water shortage. History of mankind is today standing in the midst of optimism, hope and justification. Nanofiltration, ultrafiltration and other membrane separation techniques are the torch bearers of environmental engineering techniques for the future.

Environmental sustainability and global water needs to be tackled and frontiers of difficulties overcome at its very roots. Global water shortage is a burning issue and a thought provoking focal point in the progress of human civilization. Man's vision, scientist's vision and the 
innumerable vistas of science needs to be reshaped at this critical juncture of human endeavour.

\section{Global water shortage, scientific cognizance and the application of membrane science}

Global water shortage and scientific cognizance today stands in the midst of optimism, vision and reassessment. Environmental disasters, sustainability and proper application areas of novel separation tools are ushering in a new visionary era of immense positive optimism. Water shortage in developing countries is a boon to immense disaster and has a retrogressive effect on the future economy of a nation. The target of future should be groundwater remediation and effective groundwater de-contamination. ${ }^{17,18}$

\section{Barriers to successful separation phenomenon of membrane science}

Barriers to successful separation phenomenon in the field of membrane science needs to be overcome with immediate and vehement effect. History of mankind, the effective vision and purposeful objective are the parameters to the success of membrane separation techniques. ${ }^{16,17}$

Difficulties to the future of membrane science are wide and many. Operational difficulties are setbacks towards successful environmental sustainability and success of future of membrane technology. Fouling and cleaning today stands as a major barrier but successful scientific pursuit is opening up new vistas of scientific regeneration.

\section{Limitations and obstacles of nanofiltration and ultrafiltration}

Nanofiltration and ultrafiltration today stands in the path of scientific vision and scientific steadfastness. The vision of challenges needs to be restructured and re-envisioned. Envisioning the road ahead and path of success are the inevitable parameters of growth. Limitations and obstacles of nanofiltration, ultrafiltration and other novel separation techniques are ushering in a new era of challenges and a new dimension towards validation of laboratory scale research to society. ${ }^{17,18}$

\section{Future recommended studies in the path towards progress in membrane science}

Future recommended studies in the path towards progress in membrane separation processes are opening new vistas of future scientific endeavour. The history of definitive challenges needs to be restructured. Future recommended studies will lead towards a new generation of immense scientific thought procedures. Environmental engineering and membrane science will surely lead scientific generations and mankind to a new dawn of civilization. $^{16-18}$

\section{Concentration boundary layer phenomenon}

Concentration boundary layer phenomenon today remains as a primary issue in the future performance of a membrane. The gamut of challenges in solving critical problems in membrane performance needs to be readdressed and rejudged. Technology needs to be revitalized and re-envisioned with the progress of civilization. Scientific boundaries and visionary frontiers needs a thorough reshaping. ${ }^{18}$ 


\section{Desalination, water shortage and immense vision for the immediate future}

Desalination, water shortage and the far-reaching vision in the success of performance of a membrane are the primordial issues to tackle in the immediate visionary future. An engineer's vision needs to be revamped with the crucial view of environmental catastrophes. In today's world, desalination and groundwater contamination are the interlinked technologies to solve global water shortage crisis. In South Asian and South East Asian countries, the boon to inevitable disaster is the issue of groundwater contamination and groundwater contamination.

\section{History of mankind, history of environmental engineering science and the answers to ecological balance}

History of mankind and history of environmental engineering science today has a farreaching vision which are surpassing difficulties and frontiers. The inevitable challenges needs to be readdressed and revamped. Environmental engineering in today's civilization is marching steadily towards a newer vision and newer ventures. The upshot of scientific pursuit in the field of membrane science is basically targeted towards environmental engineering science and alleviating global water shortage. Human civilisation's definition of environmental engineering science today is targeted towards ecological balance.

\section{Future vision, future of membrane science and the domain of environmental engineering}

Future vision and future of membrane science today stands in the midst of hope, optimism and scientific steadfastness. The domain of environmental engineering is gearing towards a newer vision and a newer paradigm. Desalination and global water shortage are the primordial issues to tackle for the future. History of human civilization today stands in the midst of immense catastrophes and in a similar manner immense hope and justification. Scientific vision needs to be restructured and reassessed in view of the environmental disasters and human judgement.

\section{CONCLUSION}

Global water shortage, desalination and water treatment are the visionary challenges towards a newer generation of present day human civilization. History of science and technology needs to be rejustified and reshaped. Man's vision needs to be re-organized and re-envisioned with the crucial juxtaposition of global water shortage and environmental catastrophes. Sustainable development is the only path to success. Application of environmental engineering tools such as membrane technology will open up a visionary path towards a newer future of environmental sustainability.

\section{Acknowledgement}

The author wishes to acknowledge the contribution of Chancellor, Management, Faculties and students of University of Petroleum and Energy Studies, Dehradun, India without whom this writing project would not have been accomplished. The author also wishes to deeply acknowledge the past and present teachers of Department of Chemical Engineering, Jadavpur University, Kolkata, India. 


\section{References}

[1] Kepa U., Stanczyk-Mazanek. E., Stepniak L., Desalination 223 (2008) 187-193.

[2] Zhou H., Smith D.W., Journal of Environmental Engineering Science 1 (2002) 247-264.

[3] Al-Kdasi, Idris A., Saed K., Guan C.T., Global Nest, The International journal 6(3) (2004) 222-230.

[4] Palit S., International Journal of Chem Tech Research 4(3) (2012) 862-866.

[5] Gogate P.R., Pandit A.B., Advances in Environmental Research 2004,8 (2004) 500-551.

[6] Chiron S., Fernandez-Alba A., Rodriguez A., Garcia-Calvo E., Water Research 34(2) (2000) 366-377.

[7] Kos L., Perkowski J., Fibres and textiles in Eastern Europe 11(4) (2003) 43.

[8] Suty H., De Traversay C., Cost M., Water Science and Technology 49(4) (2004) 227-233.

[9] Stasinakis A.S., Global NEST Journal 10(3) (2008) 376-385.

[10] Joseph C.G., Puma G.L., Bono A., Krishnaiah D., Ultrasonics Sonochemistry 16 (2009) 583-589.

[11] Huber M.M., Canonica S., Park G.Y., Gunten U.V., Environmental Science and Technology 37 (2003) 1016-1024.

[12] Esplugas S., Bila D.M., Krause L.G.T., Dezotti M., Journal of Hazardous Materials 149 (2007) 631-642.

[13] Palit Sukanchan, International Journal of Chemical and Analytical Science 3(1) (2012) 1290-1292.

[14] Palit Sukanchan, International Journal of Chemical and Analytical Science 3(1) (2012) 1293-1295.

[15] Palit Sukanchan, Indian Journal of Science and Technology 2(10) (2009).

[16] Palit Sukanchan, International Journal of Chemistry and Chemical Engineering 1(1) (2011) 53-60.

[17] Kantarci N., Borak F., Ulgen K.O., Process Biochemistry 40 (2005) 2263-2283.

[18] Cheryan M., Ultrafiltration and Microfiltration Handbook, Technomic Publishing Co. Inc., 1998.

[19] Google Images: www.google.com 